«HEBИЯИMOCTb" TЯKКОГО ВРEAА 3ПOPOBbIO в MOPकONOThn

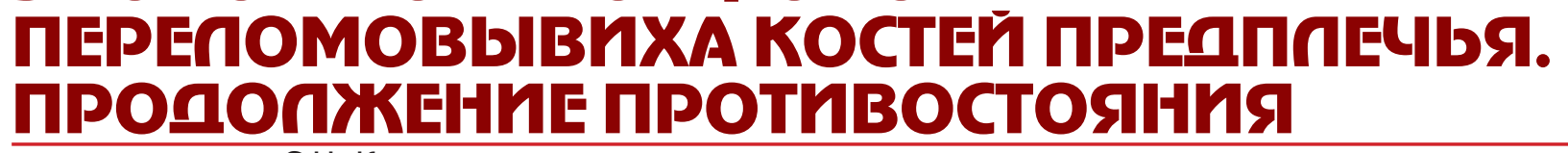
к.м.н., доцент С.Н. Куликов

Государственное бюджетное образовательное учреждение высшего профессионального образования «Самарский государственный медицинский университет» (ректор - академик РАН, д.м.н., профессор Г.П. Котельников)

Аннотация: Статья посвящена экспертной трактовке тяжести и механики образования казуса переломовывиха костей предплечья, составляющих локтевой сустав. Трактовке в режиме продолжающегося коллегиального противостояния в эпопее длительно текущего во времени судебно-экспертного процесса. Основной предмет темы состоял в противоположной оценке тяжести повреждения (вред здоровью тяжкий или средней тяжести). Принципиальное расхождение экспертных суждений по факту рассматриваемой травмы заключается в применении формулировок дефиниций п. 6.11., п. 6.11.2., п. 6.11.3., п. 6.11.11., п. 7.1. Медицинских критериев определения степени тяжести вреда, причинённого здоровью человека, утверждённых Приказом № 194н Минздравсоцразвития России, 24 апреля 2008 г. Показана важность для экспертного процесса надлежащей, а не произвольной визуализации первоначальной морфологии повреждения, задокументированной рентгенограммой по факту первого обращения пострадавшего субъекта за медицинской помощью. Констатировано упорство оппонирующих экспертов в «невидимости» очевидной морфологии переломовывиха костей предплечья, составляющих локтевой сустав.

Ключевые слова: судебно-медицинская экспертиза, заключение врача-специалиста, дефиниции Медицинских критериев тяжести вреда здоровью, Атлас судебной экспертизы тяжкого вреда здоровью, переломовывих Монтеджа, вывих костей предплечья, переломовывих костей предплечья

\title{
THE INVISIBILITY OF THE HEAVY HEALTH HARM IN THEMORPHOLOGY OF FRACTURE- DISLOCATION OF THE FOREARM'S BONES. CONFRONTATION IS GOING ON
}

\section{S.N. Kulikov}

Annotation: The article deals with the expert interpretation of the weight and the mechanism of the formation of the casus of fracture-dislocation of the forearm's bones composing elbow joint. The author touches upon the interpretation in the regime of remaining collegiate confrontation in the epic of the prolonged forensic process. The main subject of the confrontation was the opposite evaluation of the trauma weight (harm to the health grave or medium-gravity). The principle difference of the expert judgements on the fact of the discussed trauma is in the use of the definitions p. 6.11., p. 6.11.3., p. 6.11.11., p. 7.1. of the Medical criteria of the severity determination of the harm caused to the human's health approved by the Order № 194n by the health Ministry of Russia the 24th of April 2008.The author shows the importance for the expert process of appropriate but not spontaneous visualization of the initial trauma morphology recorded by the X-ray picture in case of the first patient's call for medical aid. The author stated the insistency of the opposing experts in the invisibility of the evident morphology of fracture-dislocation of the forearm's bones composing elbow joint.

Keywords: forensic medical examination, doctor's epicrisis, definitions of the medical criteria of the weight of health harm, forensic atlas of the heavy health harm, Monteggia fracture-dislocation, dislocation of the forearm's bones, fracture-dislocation of the forearm's bones

http://dx.doi.org/10.19048/2411-8729-2015-1-4-41-46

\section{$\checkmark$ ВВЕДЕНИЕ}

Непременное условие для изучения материалов этой публикации - понимание сути проблемы, подробно изложенной в статье, опубликованной в журнале «Судебная медицина» № 3 (Статья-1).

Принимая во внимание продолжительную цепь эпизодов рассматриваемых обстоятельств судебного следствия, ниже покажем принципиальную картину экспертной ситуации, не путём приведения протокольных цитат, а в форме хронологически реального повествовательного эссе, без ссылок на персональные данные.
20 мая 2015 г. Место действия - мировой суд г. D, соседствующего с Самарской областью региона.

Автор настоящей статьи, выступавший в статусе специалиста, просит потерпевшего показать суду первичный рентгенологический снимок травмы костей, составляющих локтевой сустав. См. рuс. 01. «Первичная рентгенограмма по факту причинения травмы» в Статье-1. Подлинник данной рентгенограммы был объектом изучения последней (третьей) судебно-медицинской экспертизы, выполненной в областном Бюро СМЭ соседнего с Самарской областью региона. В дальнейшем - «Рентгенограмма-1». Последняя диагности- 
ческая экспертная формулировка травмы локтевого сустава следующая: «... вторично открытый оскольчатый перелом локтевого отростка левой локтевой кости с вывихом костей предплечья.». В дальнейшем - «диагно3-1».

Пользуясь правами специалиста, автор статьи задаёт ряд вопросов ведущему эксперту в отношении последней (третьей) комиссионной экспертизы:

1-й вопрос: «Вы подтверждаете диагностическую формулировку травмы локтевого сустава, указанную вами в выводах?» Это диагноз-1.

Ответ эксперта: «Да».

2-й вопрос: «Как, на ваш взгляд, следует детализировать данный диагноз, в части указанного вами вывиха костей предплечья? Это вывих только лучевой кости, её головки, или это вывих обеих костей предплечья относительно нижнего конца плечевой кости?».

Ответ эксперта: «Это вывих только лучевой кости, одной ...».

3-й вопрос: «Посмотрите на рентгенограмму-1 внимательней. Ведь смещены обе кости предплечья относительно суставной поверхности плечевой кости ...».

Адвокат подсудимого прервал диалог специалиста и эксперта, выражая сомнения в отношении этой рентгенограммы к предмету дела. Он мотивировал это тем, что рентгенограмма в материалы дела внесена не была и появилась только в последней экспертизе. Последнее действительно так, но это касается уже другого процессуального вопроса - почему же документальный материал, прошедший через последнюю судебную экспертизу как объект исследования и идентифицированный специалистами как рентгенограмма скелета левого локтевого сустава именно потерпевшего лица, формально не был включен в перечень материалов дела?.. Замечание адвоката судом не было расценено, как факт констатации суду непредставления ему всех имеющихся материалов по делу.

При возвращении к рассмотрению 3-го вопроса, эксперт, всматриваясь в рентгенограмму-1 на просвет оконного проёма, сообщил, что никакого смещения он не видит ... Попытка уточнить, действительно ли надо понимать, что эксперт не видит смещения локтевой кости относительно суставной поверхности плечевой кости, привела к однозначному его ответу: «Нет, не вижу. Есть перелом локтевого отростка». На следующий уточняющий вопрос эксперту, действительно ли он не видит смещения локтевой кости в области перелома, был получен ответ: «Нет, не вижу».

Описанный эпизод является ничем иным, как произвольной и упорной «невидимостью» морфологии очевидного факта травмы костей предплечья. Причины этого произвольного упорства рассмотрим чуть ниже.

Итак, в отношении вывиха лучевой кости и давности его возникновения экспертное суждение базировалось на неизвестности момента его возникновения: лучевая кость вывихнулась после причинения травмы, или до момента приезда скорой медицинской помощи, или при транспортировке в больничный стационар. То есть перелом локтевого отростка, вторично открытый за счёт повреждения кожных покровов изнутри костными отломками, а не в момент причинения травмы. В момент причинения травмы перелом был закрытый. Вот почему по степени тяжести оценивали только закрытый перелом локтевого отростка. Вывих костей предплечья (вывих лучевой кости), вторично открытый перелом локтевого отростка - не относятся по времени образования непосредственно к моменту причинения травмы. В этой связи эксперты не увидели каких-либо морфологических признаков, позволяющих рассматривать данную травму по тяжести вреда здоровью в контексте п. 6.11. 194-го Приказа.

Далее эксперту был задан ряд уточняющих вопросов:

- «Морфология травмы говорит нам о механизме её образования?».

Ответ эксперта: «Да, морфология травмы говорит о механизме её образования».

- «Вы указали в последнем диагнозе травмы локтевого сустава у потерпевшего на вывих костей предплечья, т.е. обеих костей вывих, так?».

Ответ эксперта: «Да».

- «Обе кости предплечья вывихнулись одновременно или нет, или по отдельности?».

Ответ эксперта был невнятен: «Вывих лучевой кости произошёл ... потом - локтевой кости ...», что могло указать на его смутное представление логической связи между утверждаемой экспертом морфологией травмы, с одной стороны, и механизмом её образования, с другой. Адвокат потерпевшего дополнительно представил суду в предыдущем заседании ещё два заключения специалистов, выполненных тремя авторитетными судебными медиками России. Одно заключение двух специалистов и другое заключение, за подписью одного специалиста. Всё они пришли к единому мнению о том, что морфология рассматриваемой травмы локтевого сустава содержит в себе объективные признаки Медицинских критериев тяжкого вреда здоровью по п. 6.11. 194-го Приказа. О сущности экспертного понимания принципа п.6.11. Медицинских критериев, см. в Статье- 1 .

Только вопрос о деталях повреждений костных элементов, с одной стороны, и типичности их в контексте травматологических эпонимов в наименовании перелома (переломовывиха) трубчатых костей, составляющих локтевой сустав, с другой, как указали данные специалисты, требует упорядоченности.

Действительно требует. Это действие объективно и последовательно можно воспроизвести на основе дифференцированного анализа пунктов 194-го Приказа. А именно дифференцированного экспертного анализа п. 6.11.2., п. 6.11.3., п. 6.11.11.. Т.к. дефиниции данных пунктов Медицинских критериев были употребляемы в констатации признаков причинения тяжкого вреда здоровью, что фигурировало во всех шести заключениях специалистов. В четырёх заключениях автора настоящей статьи и в двух последовавших за ними заключениях специалистов, пользующихся несомненным авторитетом среди судебных медиков.

Повторим выявленный нами факт об отсутствии «классического Монтежда» в морфологии рассматриваемой травмы. Указанному факту в Статье-1 уделено пристальное внимание с детальной констатацией сравнительной рисуночной графики. См. рис. 01. 2., рисуноксхему № 4, рисунок-схему № 5 в Статье-1. Разъяснено, почему в столь длительно текущей «эпопее» экспертного «противостояния» возникли суждения о переломовывихе Монтеджа. Повторим дефиницию Мк по п. 6.11.3. 194-го Приказа, в части переломовывиха Монтеджа: «6.11.3. открытый или закрытый перелом-вывих костей предплечья: перелом локтевой в верхней или средней трети с вывихом головки лучевой кости (перелом-вывих Монтеджа)... ».

Мы уделили внимание «гипотетическому» Монтеджу потому, что данное суждение о морфологии переломовывиха имело место в период времени до момента легитимного «появления» в юридическом процессе 
первичной рентгенограммы. Той, которая была произведена тотчас по факту причинения травмы, фотокопия которой отображена на рuc. 01. в Статье-1. До появления её, как эксперты соседнего региона, так и мы, «отталкивались» только от картины «собранного» локтевого сустава после факта производства операции остеосинтеза. См. рис. 01.1. в Статье-1. При этом мы воспроизвели ретроспективно рисуночную графику морфологии перломовывиха Монтеджа. См. рuс. 01.2. в Статье-1 и дали разъяснения к нему. И если бы это было в действительности (как на рис. 01.2.), то данную морфологию следовало бы именовать «высоким» $\mathrm{MoH}^{-}$ теджем. «Высоким», потому, что перелом поктевой кости случился в проекции крайней позиции её верхнего конца, между локтевым и венечным отростками её. Вывих головки лучевой кости должен был «существовать» в изолированном виде, т.е. головка лучевой кости в морфологической конфигурации Монтеджа, должна быть вывихнута полностью, то есть, как в плечелучевом суставе, так и в лучелоктевом, одновременно. «Полностью и одновременно» - это идентифицирующий признак пеломовывиха по типу Монтеджа. Не видеть этого медико-биологического факта в конфигурации переломовывиха Монтежда может только слепой. Не увидеть отсутствия этого медико-биологического факта в запечатлённой картине морфологической конфигурации переломовывиха костей предплечья в локтевом суставе у потерпевшего на первичной рентгенограмме (cм. puc. 01. в Cmaтье-1) тоже невозможно.

Головка лучевой кости не изолирована полностью от суставных сочленений, составляющих локтевой сустав. Головка лучевой кости потеряла суставную связь только с головкой наружного мыщелка плечевой кости. Это факт. Но головка лучевой кости не потеряла своей связи (суставной связи) в лучелоктевом суставе. Тоже факт.

Дистальный отломок локтевой кости, в «союзе» с лучевой костью (в области лучелоктевого сочленения), сместился вперёд относительно нижнего конца плечевой кости. Сместился вперёд заметно выше уровня блока и головки наружного мыщелка плечевой кости. Образовался передний вывих костей предплечья. Данный вывих (именно «вывих костей предплечья», см. «диазгоз-1»), признали и эксперты соседнего региона в последней (третьей) комиссионной экспертизе. А вот центральный отломок локтевой кости, представленный целиком локтевым отростком её, остался в сочленяющемся контакте с блоковидной поверхностью и ямкой локтевого отростка плечевой кости. Перелом верхнего конца локтевой кости случился в промежутке между локтевым и венечным отростками её.

Таким образом, имеем картину переломовывиха локтевой кости в купе с вывихом головки лучевой, в плечелучевом сочленении - сиречь передний вывих костей предплечья, что произошло одновременно. Данный вывих (+ перелом верхнего конца локтевой кости) не мог произойти как-то иначе, это исключено. Морфология говорит нам о механике образования травмы, что и есть аксиома. Это третий факт.

Вот суть рассматриваемой травмы. В дальнейшем триединство фактов медико-биологического свойства было отражено нами в тексте и графике последнего третьего дополнительного заключения специалиста (от декабря 2014 года). Это отражено в рисуночной графике к Статье-1 («Третье дополнительное заключение № 03/11-14 от 12.12.-30.12.2014 г.»).

Было ли изучено содержание данного заключения нашими оппонентами (экспертами и специалистом), выступающими в суде? Уверенности нет. Возможно, оно было добросовестно изучено тремя специалистами-коллегами, давшими своё суждение по предмету данного дела (о чём мы говорили выше)?..

В этой связи констатируем, что после диалога в судебном процессе и мы, и ведущий эксперт соседнего региона, пришли к однозначному резюме: «классического Монтеджа» здесь нет.

На наш вопрос ведущему эксперту: «Добавилось ли что-либо к тяжести травмы у потерпевшего, когда к диагностируемому ранее в двух предыдущих экспертизах перелому локтевого отростка, в третьей экспертизе присовокупился ещё и вывих костей предплечья?» последовал его отрицательный ответ: «Нет, тяжесть травмы не увеличилась ... Ничего не добавилось».

20.05.2015 г. по ходатайству подсудимой стороны с заключением выступил ещё один специалист, представитель профессорско-преподавательского состава кафедры судебной медицины и права государственного медицинского ВУЗа из региона, соседствующего с Самарской областью, («специалист-2»). Его мнение было аналогично суждению его коллеги - эксперта, допрошенного до того. В ходе допроса специалиста-2 он в декларативной форме манифестировал отсутствие Монтеджа.

Очевидно: во мнениях специалистов относительно медицинских критериев п. 6.11.2., п. 6.11.3., п. 6.11.11. нет единодушного и однозначного мнения!

Так ознакомились ли с нашим последним, третьим, дополнительным заключением эксперты и специалисты? Видимо нет, хотя бы потому, что в суде стороны обоюдно задали вопрос о критическом количестве костей, составляющих локтевой сустав, которые должны «иметь» переломы, чтобы было основание применить п. 6.11.2....

При этом, в списках литературы, которые они обозначали в своих исследованиях, наши монографии, журнальные статьи, по теме АТЛАСА судебной экспертизы тяжкого вреда здоровью упомянуты не были, [1-4]. В дальнейшем - «АТЛАС».

Тогда как, например, вводная часть АТЛАСА, [1], предварена аннотацией главного специалиста по судебно-медицинской экспертизе Минздрава (Минздравсоцразвития) России, директора ФГБУ РЦСМЭ Минздрава России, А.В. Ковалёва, цитируем: «Настоящее издание является практическим пособием для судебно-медицинских экспертов и может быть использовано судом, лицами, производящими дознание, работниками прокуратуры и следователями при назначении, производстве и оценке судебно-медицинской экспертизы вреда здоровью». Сторонами ссылались лишь на отозванное письмо Минздрава России от 8 ноября 2012 г. (№ 14-1/10/2-3598), в части толкования П. 6.11.2. Медицинских критериев. Толкование дефиниции п. 6.11.2. в наших источниках представлено исчерпывающим образом, $[1,3,4]$, которое и было нами изложено в суде.

Убеждение судьи не поколебалось в части вывода последней экспертизы коллег из соседнего с Самарской областью региона о вреде здоровью «средней тяжести». Результаты допроса ведущего эксперта и его коллеги «специалиста-2» показались судье «убедительнее». Что же, по процессуальной форме всё правильно, но по сути медико-биологического факта травмы и ее морфологической структуры - абсурд.

Вернёмся к судебной медицине, к фактам медикобиологического свойства, к их ключевой сути в предмете рассмотрения данного дела. Объектом экспертного восприятия, прежде всего, считаем первичную рент- 
генограмму травмы. Рассмотрим её ещё раз (puc. 01. в Cmambe-1).

В данном объекте отчетливо видно наличие триединства фактов медико-биологического свойства. В чем же причина столь стойкого нежелания их видеть здесь у наших коллег-оппонентов?..

Именно ключевую суть морфологии травмы мы намеревались озвучить в резюмирующем заявлении специалиста на суде, но суд нам в этом отказал. Однако ничто не помешает опубликовать его на страницах отраслевого издания, чтобы все-таки найти правильный ответ.

Итак, на основе МКБ-10 проведём дифференцированный экспертный анализ п. 6.11.2., п. 6.11.3., п. 6.11.11. 194-го Приказа [1-4].

Дифференциальный экспертно-морфологический анализ характера рассматриваемой травмы локтевого сустава по п.п. 6.11.2., 6.11.3., 6.11.11.

В итоге наша формулировка диагноза рассматриваемой травмы остаётся неизменной. См. Статью-1 и Рисунок-схему № 6 в ней.

«Открытый передней вывих обеих костей предплечья с унифокальным внутрисуставным оскольчатым переломом верхнего конца локтевой кости в промежутке между локтевым и венечным отростками её.». Это диагно3-2, по содержанию Статьи-1.

Формулировка диагноза-2 полностью соответствует п. 6.11. 194-го Приказа, применительно к первой части п. 6.11.11. Медицинского критерия тяжкого вреда здоровью, в его непосредственном значении ведущего морфологического признака: передний вывиха костей предплечья в локтевом суставе. Где в обязательном порядке следует рассматривать (и присовокуплять сюда) неполную (частичную компиляцию) дефиниций п.п. 6.11.2. и 6.11.3. Медицинских критериев тяжкого вреда здоровью. См. таблииу.

В части чего? В части унифокального перелома верхнего конца локтевой кости (неполный компилятивный признак п.6.11.2.), что определяет форму вывиха костей предплечья в данном казусе травмы, как переломовывих.

И рассматривать в части вывиха суставной головки лучевой кости, но не изолированного от всех суставных поверхностей (плечевой и локтевой костей), а только от суставной поверхности плечевой кости. Плюс к тому унифокальный перелом верхнего конца локтевой кости. Не полные (не состоявшиеся полностью) морфологические элементы первой части п. 6.11.3. («классического Монтежда»).

Допустимость компоновки формулы морфологии рассматриваемой травмы из морфологических элементов п.п. 6.11.2., 6.11.3., 6.11.11., с выбором ведущей дефиниции первой части п. 6.11.11., проведена нами сообразно разделу «Заключительных положений» 194-го Приказа: пункту 10, пункту 11, пункту 13.

Пункт 10 гласит: «Для определения степени тяжести вреда, причинённого здоровью человека, достаточно наличия одного Медицинского критерия».

Пункт 11 гласит: «При наличии нескольких Медицинских критериев тяжесть вреда, причинённого здоровью человека, определяется по тому критерию, который соответствует большей степени тяжести вреда.».

Пункт 13 гласит: «В случае если множественные повреждения взаимно отягощают друг друга, определение степени тяжести вреда, причинённого здоровью человека, производится по их совокупности».

Указанные пункты 194-го Приказа составлены с учетом того, что невозможно (и не нужно) прописы- вать в номенклатурном перечне морфологий травм под пунктом 6.11. (в формулировках дефиниций каждого Медицинского критерия), все мыслимые элементные морфологические комбинации (именно комбинации), повреждений ОДС, которые может «преподносить» текущая практика. Данные комбинации мы (эксперты) обязаны видеть, в этом состоит экспертная работа. И в данном перечне 194-го Приказа, и в соответствующей рубрикации XIX раздела МКБ-10 достаточно «кубиков», из которых можно сложить структуру травмы любой конфигурации.

Напомним диагноз-1, см. выше: «... вторично открытый оскольчатый перелом локтевого отростка левой локтевой кости с вывихом костей предплечья». Формулировка его обозначена в выводах к последней (третьей) судебной экспертизе.

Суть аргументации наших коллег-оппонентов состоит в том, что «имеем» только перелом локтевого отростка, вывих костей предплечья «ничего не добавил к тяжести травмы», к тому же «неизвестно» когда образовался вывих головки лучевой кости, локтевая кость в области перелома «не имеет смещения».

Вопрос об «открытости» («закрытости») травмы локтевого сустава у потерпевшего субъекта по визуализации представленной нами таблицы не имеет смысла. Почему?

Потому что «Вторично открытый ... перелом ...»это тоже открытый перелом. И главное: учитывая то, что морфология рассматриваемой травмы, так или иначе, пересекается с морфологическими элементами п.п. 6.11.2., 6.11.3. Мк 194-го Приказа, где речь идёт как о закрытых, так и открытых повреждениях опорно-двигательной системы локтевого сустава (см. таблищу), вопрос об «открытости» («закрытости») травмы в принципе неактуален.

Далее о том, что нами кратко было изложено в суде в отношении вопроса по п. 6.11.2.

Локтевой сустав чрезвычайно чувствителен к травмам, даже не сопровождающимся повреждением целостности костей его составляющих. И, как отмечают врачи-травматологи, даже при своевременном оказании специализированной помощи не всегда предсказуем исход его повреждений (любой степени выраженности - иногда возникают стойкие тяжелые контрактуры локтевого сустава даже при ушибах. Отсюда, переломы верхних сегментов, казалось бы, «не таких уж и крупных трубчатых костей», какими являются кости предплечья, следует относить к элементам морфологии данного Медицинского критерия.

Переломы костей, образующих локтевой сустав, наблюдают часто, их относят к тяжелым, сложным повреждениям. В травматологии и судебной медицине придерживаются единой классификации переломов костей, образующих локтевой сустав. Различают внутри- и околосуставные переломы. Внутрисуставные переломы включают чрезмыщелковые (Т-образные) и межмыщелковые (V- и Y-образные). К околосуставным (внесуставным) переломам относят надмыщелковые переломы плечевой кости.

Тяжкий вред здоровью необходимо устанавливать при следующих видах переломов дистального отдела плечевой кости и проксимального отдела обеих костей предплечья, составляющих локтевой сустав:

I - Переломы дистального отдела плечевой кости [см. выше на рис. 6.11.1. (1) ориентиры костных элементов дистального кониа плечевой кости - надмыщелки, мымщелки и пр.]. 
Дифференциальный экспертно-морфологический анализ характера рассматриваемой травмы локтевого сустава по п.п. 6.11.2., 6.11.3., 6.11.11.

Таблица 1

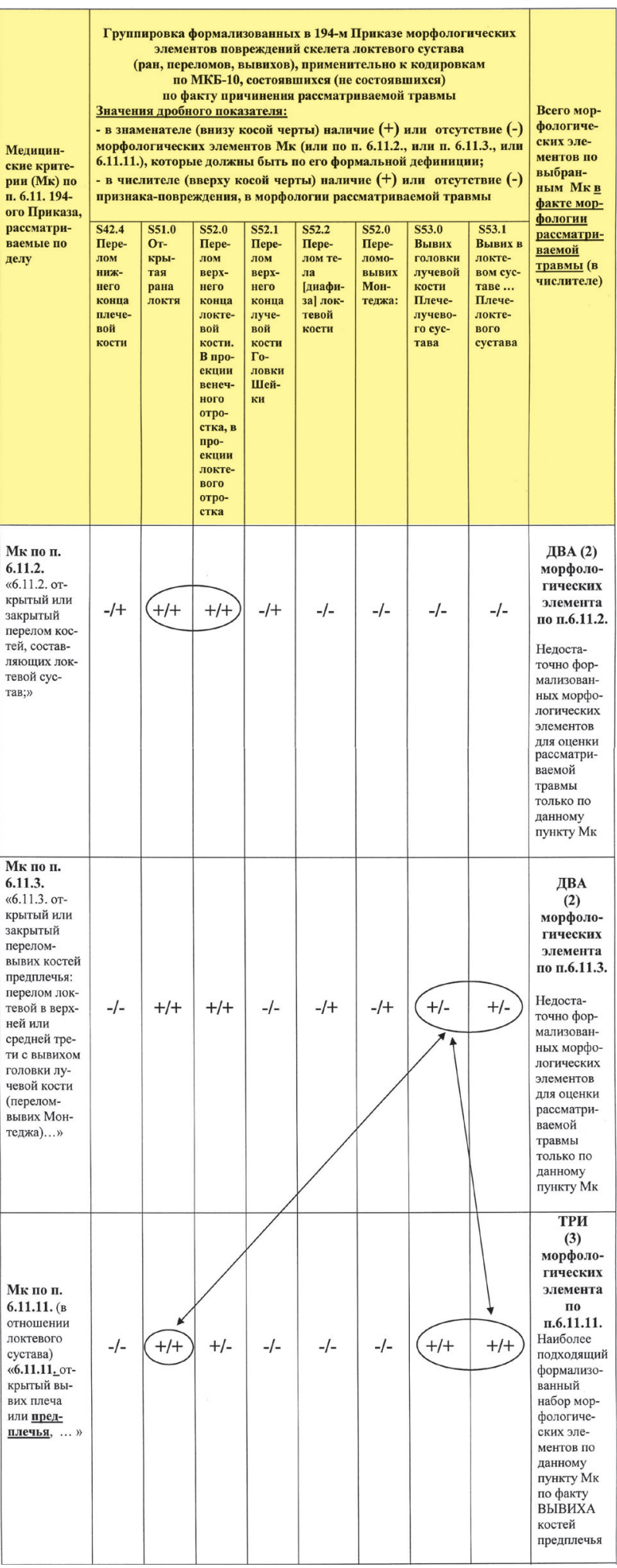

Для установления тяжкого вреда здоровью достаточно одной из следующих конфигураций переломов дистального сегмента одной только плечевой кости:

- околосуставные переломы (надмыщелковые), как поперечные, косопоперечные, так и оскольчатые: только надмыщелковые переломы с плоскостью излома, проходящей дистальнее тела плечевой кости без

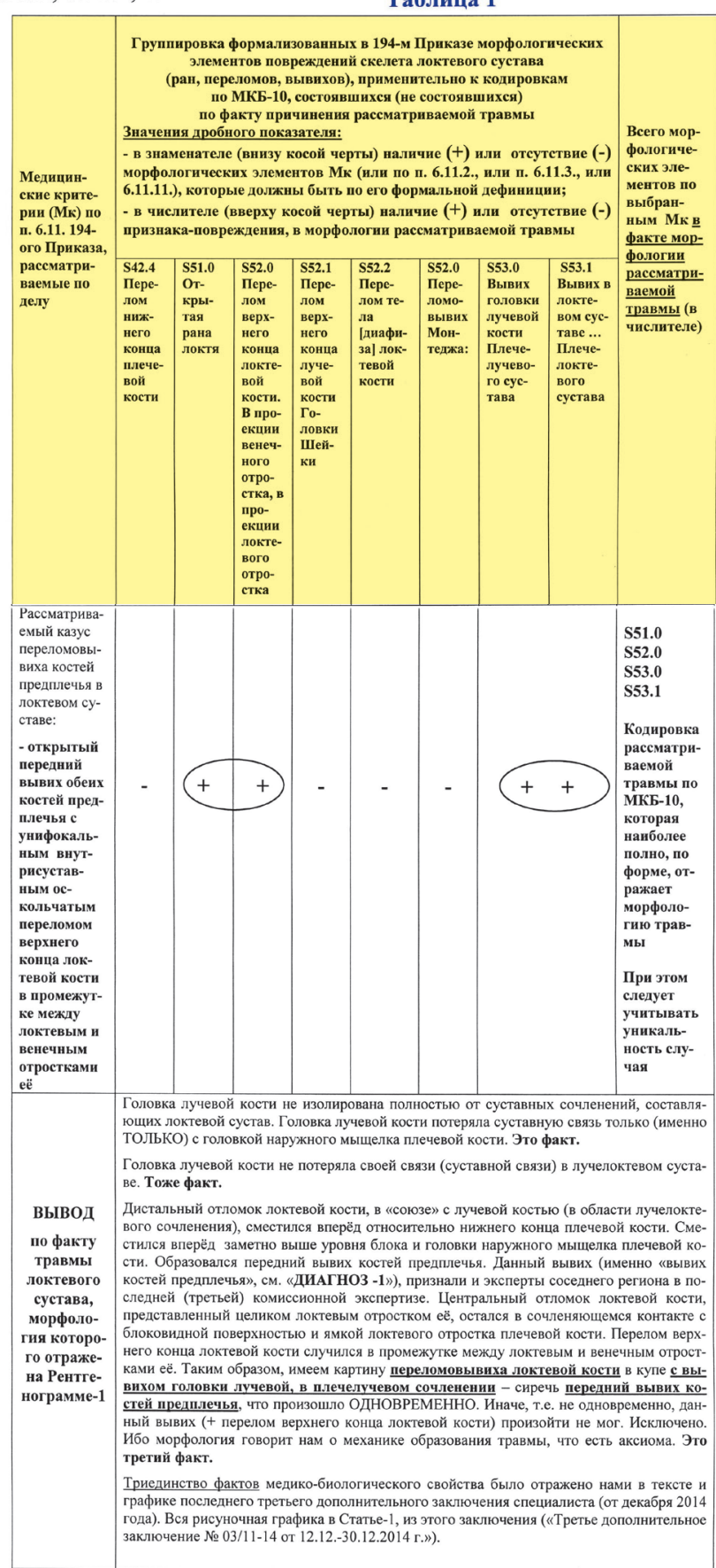

нарушения внутрисуставной части мыщелка (головки и блока плечевой кости), т.е. выше уровня внутрисуставной части мыщелка, но обязательно включающих в свою морфологическую структуру оба надмыщелка (наружный и внутренний);

- внутрисуставные переломы (ирезмыщелковые): чрезмыщелковые переломы головки мыщелка и (или) блока плечевой кости, неполные или полные, или оскольчатые; линейные (краевые) переломы мыщелка плеча, а также переломы мыщелка Y- (V-) - образные, или Т- образные, или полный оскольчатый перелом мыщелка плеча. Обязательным условием отнесения указанных переломов дистального сегмента плечевой кости к ТВ3, является такая конфигурация перелома 
мыщелка плечевой кости, которая распространяется на её суставную поверхность.

II - Переломы проксимального отдела обеих костей предплечья [см. ниже на рис. 6.11.2. (1) ориентиры костных элементов проксимального кониа локтевой кости и проксимального кониа лучевой кости].

Тяжкому вреду здоровья будет соответствовать также внутрисуставной перелом проксимального отдела костей предплечья, составляющих лучелоктевой сустав, даже без «сопровождения» одним из выше указанных переломов дистального сегмента плечевой кости.

Для отнесения переломов проксимального отдела костей предплечья к ТВ3, условием является наличие внутрисуставного оскольчатого (и даже не оскольчатого) перелома обеих костей предплечья (лучевой и локтевой).

В связи с чем мы развиваем мысль в этом же векторе: почему в случае с травмой коленного сустава достаточно наличия перелома одной из костей, составляющих коленный сустав, а в случае с локтевым суставом надо иметь в виду «связку» из двух костей предплечья?

С точки зрения биомеханики, сопряженные концы костей любого сустава должны соприкасаться, т.е. вступать в контакт всей своей суставной поверхностью, а не частью ее. Например, дистальный конец бедра опирается на проксимальный конец большеберцовой кости, при этом в контакт вступают суставные поверхности по всей площади одноименных мыщелков указанных костей и, следовательно, в случае перелома «коленного сустава» достаточно будет одного перелома одной из костей, составляющих коленный сустав: бедренной или большеберцовой.

Конфигурация и биомеханика локтевого сустава является более сложной, чем коленного. Головка мыщелка плечевой кости сочленяется с головкой лучевой кости, а блок мыщелка плечевой кости - с головкой локтевой кости. В свою очередь проксимальные концы костей предплечья сочленены между собой лучелоктевым суставом. Таким образом, суставная поверхность дистального конца плечевой кости, образованная головкой и блоком ее мыщелка, вступает в контакт с единой суставной поверхностью, образованной сопряженными костями предплечья. Следовательно, в случае перелома «локтевого сустава», в отличие от коленного, необходимо наличие переломов обеих костей предплечья.

Не оценивают как тяжкий вред здоровью, т.е. не попадают под действие п. 6.11.2. Мк, изолированные одинарные переломы костных элементов дистального (околосуставного) отдела плечевой кости и проксимального (околосуставного и суставного) отдела костей предплечья:

Плечевая кость [см. выше на рис. 6.11.1. (1) костные элементы дистального кониа плечевой кости - надмыщелки, мыщелки и пр.]:

а) изолированные переломы обоих надмыщелков (не объединённые общей линией излома), они не затрагивают конфигурацию суставной части мыщелка (сам мыщелок, его головку и блоковидную поверхность);

б) изолированный перелом одного надмыщелка (не распространяющийся на мыщелок, головку и блоковидную поверхность);

в) отрыв внутреннего надмыщелка с ущемлением его в полости локтевого сустава.
Локтевая кость [см. ниже на рис. 6.11.2. (1) костные элементы проксимального кониа локтевой кости]:

a) изолированный одинарный перелом локтевого отростка (независимо от распространения линии перелома на суставную поверхность локтевого отростка);

б) изолированный одинарный перелом венечного отростка (независимо от распространения линии перелома на суставную поверхность блоковидной вырезки локтевой кости);

в) изолированный перелом бугристости (независимо от распространения линии перелома на суставную поверхность блоковидной вырезки локтевой кости).

Лучевая кость [см. ниже на рис. 6.11.2. (1) костные элементы проксимального кониа лучевой кости]:

a) изолированный одинарный перелом головки (независимо от распространения линии перелома на суставную окружность головки лучевой кости);

б) изолированный перелом шейки (независимо от распространения линии перелома на суставную окружность головки лучевой кости).

в) изолированный перелом бугристости (независимо от распространения линии перелома на суставную окружность головки лучевой кости).

Таким образом, вопрос о том: «Какие же переломы, каких костей, и в какой комбинаиии попадают под действие настоящего пункта Мк» для судебно-медицинского эксперта будет снят, если он внимательно и надлежащим образом проанализирует толкование практической текстовой дефиниции Мк по п. 6.11.2. в совокупности с иллюстрациями к ней. $[1,4]$.

Отсюда следует, что судебно-медицинскую часть вопроса возможно представить зримо (в рисуночной графике) и доказательно.

Чем ознаменуется окончание данного юридического процесса - пока неизвестно, однако все заинтересованные специалисты будут о нем проинформированы.

\section{$\checkmark$ ЛИТЕРАТУРА}

1. Клевно В.А., Куликов С.Н., Копылов А.В. Медицинские критерии вреда здоровью. Дефиниции и иллюстрации: АТЛАС/ [Клевно В.А., Куликов С.Н., Копылов А.В.; под ред. проф. Клевно В.А.] - М.: РИО ФГБУ РЦСМЭ Минздравсоцразвития России, 2012.-367 с.: ил. - С. 3, С.С. 302-306; С. 334. ISBN 978-5-903341-17-7

2. Клевно В.А., Куликов С.Н. Границы содержания и доступность толкований практических текстовых дефиниций Медицинских критериев вреда здоровью /Клевно В.А., Куликов С.Н. // Судеб. - мед. экспертиза.— 2012.- № 5. - С.С.49-52.

3. Куликов С.Н., Ардатов С.В. Элективы судебной экспертизы вреда здоровью. Анализ экспертных эпизодов из практики правосудия: монография / С.Н. Куликов, С.В. Ардатов. - Самара: ООО «Самара Люкс Принт», 2012.- 340 с.: ил. - С.С. 24-39; С.С. 177-186; C.C. 190,191 ; C.C. $233-238$. ISBN 978-591830-061-9

4. Куликов С.Н. АТЛАС судебной экспертизы тяжкого вреда здоровью / С.Н. Куликов. - Самара: изд. НОАНО ВПО СИБиУ, 2012.- 316 с.: ил. - С.С. 107-123; C.C. 158-163. ISBN 978-5-902922-23-0

Для корреспонденции

кУликов Сергей Николаевич - доцент кафедры судебной медицины ГБОУ высшего профессионального образования, «Самарский государственный медицинский университет» МЗРФ, к.м.н., врач по специальности «Судебномедицинская экспертиза» высшей квалификационной категории, юрист, г. Самара, Россия. Член-корреспондент ВАНКБ. Адрес: г. Самара, 443056, ул. Московское шоссе, д. 2, кв. 72 . +7 927 202-36-02; факс: (Самара) +7 $846337-$ 80-70; дом. тел. +7 846 265-14-15•E-mail: pretor_kulikov@mail.ru 